\title{
Educational Transformation through TVET
}

\author{
Prem Prasad Sigdel \\ Tri-Chandra Multiple Campus, Department of English
}

\begin{abstract}
Transformation in education is possible through vocational education as it has taken diverse responsibilities to promote employment in the society. Its motto is to address the need of an individual at local level so that the transformative motto of education can be met. The process of transformation starts from person, then it transforms the society; ultimately, it transforms the nation. Work-based learning can transform an individual from the ideals of theoretical education which is often known as formal education. In transformative education, the responsibility of instructors directs accordingly to focus students in local course and context. TVET has established a new fabric in such context so that we can transform an indifferent, inactive, unemployed person to laborious, active and engaged one. The motto of transformative education is to respect own work so that one can realize change and contributes in course of development. TVET education would rationalize when we can implement local based curriculum with field-work. Secondary sources have been consulted to develop the article. Mostly, the way of transformation has been focused with literatures.
\end{abstract}

Keywords: Transformation, work-based learning, lifelong learning, social practices.

DOI: $10.7176 /$ RHSS/11-1-03

Publication date: January $31^{\text {st }} 2021$

\section{Introduction}

Education ensures freedom in our life fulfilling individual needs according to the interest of the learner. We need such education that can transform our life from traditional norms to the modern practicable world. The prime motto of education is to guarantee absolute freedom putting aside the 'outmoded' and 'arcane' practices to new collaborative, inclusive and diversified knowledge (Apelgren, Burnard \& Cabaroglu, 2015). Fruitful learning can be achieved if we could include the ideas and views of individual in a group. The traditional approach of teaching is useless as it hasn't been able to address diverse needs of students. To relieve from it, we need collaborative, participatory, and work-based learning approach which can be taken from learners' own life experiences.

Learners can participate in a stimulating debate in the classroom or in their work areas since they are at the center of learning in transformative teaching/learning process. Technical and vocational education and training (TVET) offers people such an opportunity to create forum to involve as co-participants in work-based activities. The role of instructor is to be supportive to develop positive thinking, feeling, perceiving, and understanding of students (Kemmis \& McTaggart, 2007).We need effective and systematic education which can address different aspects of life. The education which can't guarantee employment in this era is useless. Either we call it practical or behavioural education; we need adequate environment to acquire such education in $21^{\text {st }}$ century. Stone and Davidson (2015) suggested three qualities of an inclusive teaching as: knowledge of learners of their social contexts, understanding of curriculum content and goals, and understanding knowledge of diverse learners. In this way, learner should be an active agent to get "any sustainable innovation" in their life (Zuljan \& Vogrinc, 2010). Hence education could guide students not to foster traditional content rather it focuses on forming new ideas, beliefs and attitudes.

Society is the construction of different ideas, goals, abilities, or characteristics. The duty of today's education is to address 'diversity' or 'multiculturalism' of the local level as per the need of different class, age, caste, race, etc. (Slavich \& Zimbardo, 2012). Hence the responsibility of modern education is to satisfy different needs of learners going beyond the content related traditional books. Work-based learning can initiate the understanding between workers, mentors and workers, producer and marketer and so on. In other words, work-based learning creates a collaborative social lab among different stakeholders of different cultures, attitudes, behaviors, and practices. In this way, we need to create new social fabric to vitalize the TVET education in our society as it is the leverage of employment. Work-based learning "is not merely about learning, it is about knowledge production among socially committed groups" (McTaggart, 1994).

The academic environment of any learner has been affected by their cultural values and they need positive environment to get better output (Romero et al., 2008). It means learners can learn best in their own social context so the responsibility of government is to habituate them to their local context and to make society more engaging, effective, efficient, inclusive, collaborative, and so on for rapid development of the nation. The following topic is going to focus on the changing mindset of the learner in the new era as one of the aspects of transformative education. 


\section{Change in Mindset}

The new era has been guided by knowledge economy which has been existing at present in knowledge based society. We need to change our mindset along with the demand of changing time. Individual mindset needs a seachange in this context to meet requirements of this era because individual transformation is much more important to change the society and nation. Unless we don't satisfy an individual and evoke change from them, we can't achieve the goal of transformation. Education is an important vehicle to bring reform in the society which would be able to change traditional norms of the society. Education with codified pedagogies can't do it; thus, we need dynamic, motivating, regulatory, intensified, inclusive, and diverse mindset to have maximum output from education. Through education we must be able to produce an entrepreneur who has high aptitude, possessing innovative characteristics, and leader of the society to get better output. So we need to develop individuals who want to work themselves independently which is possible only with transformed education.

The disadvantaged group in the society which has been looked as the main participants of TVET education could maintain social relations, power and equality with transformed education (Bhandari, 2013). Similarly, marginalized, disadvantaged, women and disabled people can also get chance to learn from mentors with the process of work-based learning. Thus the context has changed in which we can get suitable output from such education to bring enormous change in the society. The change is possible only when we can utilize all the resources with communal effort at local level. The developed countries have made upper secondary vocational education general to their students to broaden their mind academically and in work-based learning. They have been able to mingle two rival sets of education to solve the present academic problem of low and high status of TVET and general education respectively. The level of formal education has got much value due to its nature and recognition among public; but it has been failed due to insecure job opportunity. We need transformational approach to bring change in the education system to make people realize or to eliminate the complexity of people about vocational education.

The concept towards vocational education has been changing as it has also included "personal characteristics, general competencies and specific vocational skills" (Maclean \& Pavlova, 2013, p. 57). They identified three components of vocationalization: "learning for work (work-related knowledge, practices), learning about work (settings and conditions), and understanding the nature of work (sociocultural, economic and political forces that influence work" (p. 60). They clearly state about the importance of practical based transformed education of TVET through work-based practice. However, there is no proper counseling system regarding vocational education and it is failed to motivate students due to the lack of understanding of people in developing countries. There are several problems like no provision of $\mathrm{NQF}$, poor quality of courses, need for updated curriculum, unqualified teachers and no local based curriculum in vocational education. We need to improve such condition to bring change in TVET courses.

Manpower requires soft skills, such as problem-solving, communication and work ethics with the mixture of vocational education to be transformed instead they remained rigid. There is indispensable connection of vocational education with lifelong learning to get better output in this era. Lifelong learning is a process of knowledge which is supported by the vocational education to step up the ladder so that the motto of transformational education can be achieved in no time. The policy of government requires focusing on changing the structured mindset of the individual to make TVET education more reliable among stakeholders. It has become weaknesses from government and personal side not to understand the importance of soft skills. The developed countries have understood it on time and they have started dual education system to prepare their people for the world of work and higher study as well (Adhikari, 2013).

In general, education is understood as preparation for life whatever form it may have taken. The main motto of education is to orient a person to do dignified job and to run their life or family prospects. Vocational education has supported that crucial aspect of human mindset though it has been regarded as inferior type of education to formal education. Vocational education is different than the training program as it has taken the side of lifelong learning process building confidence in learner. It is being unattractive due to the influence of elite education or it has been totally restricted in developing countries to be mixed with general education. In other words, it can't satisfy the self-esteem of the rich so that it has been sidelined though it has various positive aspects. TVET is a popular demand of the employer and the employee because it has created the manpower according to the demand of industry and the sustenance priority of common people. So it is against the elite concept of education as it has supported the grass-root people for their sustenance (Winch, 2013).

On the other hand, we can make TVET courses desirable for higher educational attainment and to address the need of labour market. Some scholars or educationists have been feared whether the share of general education would be taken by TVET. They can be doubtless as it can work without interfering the scope of general education because general education has played an important role at the prime stage/phase of students. If the background of general education is weak, vocational education can't progress well. However, most of the countries have managed NVQ to allow access of vocational education to higher educational attainment. Furthermore the aim of TVET at present would legitimize the informal traditional apprenticeship into mainstream contesting with elite education 
system. The traditional rural crafts, manufacturing, fisheries, floriculture, horticulture, pottery, agriculture etc come under this category. Educational policies and the stakeholders need to address the importance of it to be transformed to the non-elite education.

Learning from informal process in life is rich and adaptable in various other contexts that help in lifelong learning or transformation. Individuals have the capacity to construct knowledge through environments and the activities they have done. It means that we can't experience the heaven unless we aren't dead. We can learn the things either it may be positive or negative incidents that we have faced in our life. In this way, we can prepare students for the world of work with changing mindset like "informing decisions about career selection through practice-based experiences; orienting students to the world of work; and enabling students to experience work in their preferred occupations" (Billet, 2013, p. 144). The approaching subtopic has emphasized on the lifelong learning with the help of TVET.

\section{Lifelong Learning of TVET}

Etymologically, lifelong learning is a sustained approach of education with the mixture of life+long i. e. continuation till our life span. The knowledge which we have learnt in young age will have been carrying throughout the life. 'Well beginning is half done' is relevant in this context so we need better education to sustain our life properly. TVET supports for lifelong learning if we have mixed it with formal education to have maximum utilization. The often neglected TVET also needs connection with formal education to increase attraction. We can view it as learning by doing method so that people can have learnt it with wide range of possibilities. People seek decent opportunities in their life so they have attraction towards formal education to TVET. So the existing provision of TVET education has been taken second-chance education after formal education despite its positive qualities. Truly speaking, entry into existing apprenticeships seeks higher general academic criteria which is impossible for disadvantaged, marginalized, poor, socially excluded, and minority people. TVET has been neglected by the middle class and elite people so we can establish new social fabric to promote work-based education (Gamble, 2013). Thus lifelong learning is deemed necessary for any individual to mitigate poverty and to solve the problem of social exclusion.

Entrepreneurship development is one of the transformative processes of TVET which has ability to turn ideas into action. We need to develop key competencies in young people making them more creative and self-confident. The main aim of TVET programmes is to increase the employability of any person who could ultimately contribute for family, society, and the country. We can take TVET as "the master key that can alleviate poverty, promote peace, conserve the environment, improve the quality of life" (UNESCO, 2004 as cited in Badawai, 2013). However, the social structure of developing countries indicates that vocational education could prepare only paid employee. In contrast, focus can be directed for innovative and creative mind to establish enterprise. We can change our social edifice to establish own enterprise which has $90 \%$ contribution in the national economy of developed countries (Badawai, 2013). Hence we could enhance students with lifelong learning so that they have broad mindset to establish enterprise rather than being paid workers. Reports prove that TVET graduates have been able to establish much more SMEs in comparison to general education graduates. Hence, vocational education helps in decreasing the dependency ratio of the population so that we can change the existing structure of the society to more working, employable, entrepreneur, busy and developed one.

Work-place learning has several benefits as co-learners can create the situation along with the mentors that can be headed towards lifelong learning practices. Those who have adopted the lifelong learning practices in their life can have transferable occupational knowledge. It can change the context of developing society at a greater speed. Young learners need more assistance as they are novice in the workplace in comparison to the experienced one. Mostly, vocational educators come from industrial or entrepreneurial background who have good understanding of working environment. So they can orient them as lifelong learner along with their need and the demand of situation. It could transform them as entrepreneur so that their life would be secure. In the next topic, work-based transformational learning is analyzed.

\section{Work-based Transformational Learning}

Transformational learning can also be understood as work-based or experience-based learning that enables the learner to be active themselves. It is different because it has challenged the rule of packaged or textbook teaching. The information dissemination is changed into information acquiring process with personal effort. The work-based learning system is one of the elements of vocational education and training which has close relation with the learner and the field. It involves learners in the field which increases their confidence so that they can understand the benefit of job and labour market. After all learners and instructors are the creators of the labour market which is known as physical as well as perspective transformation. The role of the instructor is also directed to make students aware of their capacities and let them adapt with the labour market. Ultimately, their real guru will be the master craftsperson who has got expertise on apprenticeship and school teacher can only be the facilitator. Those learners have got knowledge about informal mechanisms of the labour market and help in transformation from training or 
educational institution to the workplace.

It needs pedagogical transformation first to transform the concept of education. A powerful or transformed pedagogy can develop "basic work habits, occupational identity and specific occupational competences" (Sweet, 2013, p. 191). It can be possible only in vocational education and training unlike in formal classroom practices. Not disturbing the basic motto of general education, vocational education can "motivate disadvantaged, disengaged and failing students, develop generic skills such as initiative and problem-solving, and teach entrepreneurship" (p. 191). In this way, vocational education can direct a person towards transformation in which the learners can identify their capacity and interest working in the field.

The popular philosophy of 'learning by doing' is typically a basic element of vocational education and training which has been deliberately ignored by policy makers. People have lip pretention that education should be practical or behavioral. However, they wouldn't accept the reality of vocational education and training due to its conceptual framework. Learning by doing lies at the base of all principals of teaching which people don't take easily as they have been influenced by theoretical education. We can claim that the concept of people and basic purpose of knowledge are paradoxically voyaging in opposite direction. Hence knowledge lies at the back of us rather we have been pursuing it ahead so we are always feeling lack of transformation. The uncodified version of practice is overshadowed by the codified, theoretical and traditional pedagogy (Gamble, 2013).

There is a rapid change in the world of work so we should make change ourselves in career development. It requires new competencies to track such problem orienting students towards achieving such competencies to get right path in their career. Students can recognize such possibilities through their own vigor so that they can be fit to the world of work. They can even recognize the better fitting job to them which is the motto of transformation from grass-root level. Students can know more what they have enjoyed most so that it will be counterproductive to thrust them other's ideas. If we can orient them towards self-employment and entrepreneurship development with vocational education and training, it can be the best achievement of our education system. Hence, they can develop the sense of 'my career is my business' which would transform them from their existing norms of education and understanding (Watts, 2013). Learning through practice or work is a common, persistent and prominent agreement of occupational education in the world of work. Engaging in work, people can know the "conceptual, procedural and dispositional occupational knowledge" needed for them to improve their capabilities required for their adult life (Billet, 2013, p. 129). In this way, learning is a constant process both in and out of the educational institutions, and in work places which can enhance for lifelong learning. The next topic is going to spot light on individual transformation with TVET education.

\section{TVET and Individual Transformation}

Knowledge and skills that help to change individual and their environment can be considered as transformation of education. Eventually social and national environment has been transformed from individual effort; so we have focused on individual transformation at first. Education and experience play a pivotal role to form such attitude in a person as education provides knowledge and skills which is essential to adapt change around them (Cavanagh, Shaw \& Wang, 2013). When people are able to live happily and independently improving their living standard, their environment and society are transformed. The knowledge and skill which can enhance people to be independent can be achieved with the combination of vocational skills and formal education. Local vocational skills make people more independent leading them for self-employment utilizing the local resources. Ultimately they can taste the elixir of vocational education with local taste. However, the aim of such vocational skills should lead people to enhance the concept of lifelong learning opportunities. Getting skills is difficult which can't be gained from formal schooling only. Individual basis vocational education can engage people at their local areas which can transform their attitude along with the understanding of education (Kafle, 2014). Acquiring skills is a lifelong process, but they should have changed themselves as society evolves gradually.

Personal transformation is a dynamic concept which can occur in different places from educational institution to the environments that society provides them. It aims at perspective transformation not physical change of any person through vocational education. Here we could understand that physical change is just a change whereas perspective change is transformation in person. In other words, physical change can provide amenities to the person but perspective change can provide inner peace. People themselves are dynamic process of change which will start from a person who can be a leader at their local areas so that others follow. Education along with vocational skills plays a vital role in transformation. It is evident that vocational education doesn't reproduce culture rather it helps in cultural production either by commercializing traditional skills or by making people aware about new knowledge and skills (Cavanagh, Shaw \& Wang, 2013).. Our physical environment and cultures form our life; however we need to transform it along with education and the skills what we have learnt. Certainly we can't discard the idea of education but we should raise question as: what sort of education? Vocational education has such capacity to change or transform traditional norms, values and rules. Only new ideas and knowledge can help in cultural production which can transform us from conventionality to modernism.

While discussing about education we can't ignore teachers who need to be transformed first with continual 
reformation from training and understanding different cultures and contexts. Here we would understand teachers' knowledge to utilize local curriculum seeking ideas from international practices. The central point is that there can be a close and collaborative relationship among schools, training centers, communities and individuals in which local ideas, knowledge, and technologies would get first priority to be used. If we see the historical development of education, we could find didactic system of teaching delivering information what is prescribed in the text (Maclean \& Pavlova, 2013). Now we need to break the system and go to local areas or individuals to understand their knowledge and capabilities for transformation. It has been getting somehow different shape in some sense from government's side as there is the development of community learning centers (CLCs) which are not sufficient at all. We need to identify certain ways of learning which can encourage individuals to learn as per the need of their understanding at the local level. As a corollary, the philosophy of capitalism has been challenged and we will be able to follow the alternative model of learning. The subsequent topic is going to explain about social transformation, a step further, from individual transformation.

\section{Social Transformation through Educational Transformation}

The role of education is to contribute for social development through educational transformation. We need to change individual first, then at the community level; their impact on society and environment would bring colossal change. Education is only the factor that can uplift illiterate, unhealthy, malnourished, marginalized and oppressed people from their existing status to the improved one. We need food, clothes, and shelter for living whereas education is the most valuable asset for those people that works as coverlet. So the value of education is incomparable and like omniscient while living common social life. TVET education thus enables these people to pursue opportunities for job or businesses or even enterprise development. General education is sufficient to make people aware about these processes whereas TVET education is about skill enhancement. In other words, general education prepares background whereas TVET would aim for outcome. Educated people can strengthen the situation of employability which would help them bringing authentic change in the society. Education is the process of construction and reconstruction of experiences of any person who can evoke for change in the social environment. Formal education has got set curriculum or it is general in scope and function, but transformational education is individual focused or it has taken different shape, size and concept to be framed.

One size fit all educational courses can't bring change in the society in comparison to diverse education. Transformational paradigm has addressed grass-root issues vitalizing local knowledge, skills and technologies. It helps on the promotion of alternative ideas challenging set norms and values of the society. Vocational education is alternative education which would help to establish new rules in the field of education and employment. We can find original resources at the local level that requires local vocational education and training to utilize properly and effectively (Rood, 2014). It is totally a new paradigmatic approach in the field of education in which new environment and culture is developed differently. Different individuals may need different sorts and levels of support which is the motto of transformative educational process. In the past, education, social norms and cultures were dominated by traditional hierarchical system, but now it becomes diverse, collaborative and inclusive. In a nutshell, it's better to leave educational planning to the local experts, principals, teachers, community leaders and so on to revitalize local culture in education.

What the communities have deemed sprouts from base that can be framed according to their need where the government can play the role of facilitator supporting with few experts for short term only. It would help in modernization and to cope with the international arena for its promotion and adverting. It would be better to handle such management to the local level in the long run. Community involvement like market day, fair or festivals help them to identify and discuss their processes (Cavanagh, Shaw \& Wang, 2013). As instructors play the role of facilitator for students in transformational education, the government can play the same role for local level for local transformation. Certainly, it will have positive result by providing subsidies, bonuses and incentives to mange TVET education in local level. As a corollary, it would improve the condition of local people improving their job prospects and livelihood at the vicinity.

Work-based learning is the form of transformational learning which would begin from home to the community or to the nation. The combination of students' experience and learning inside the school can be one of the powerful ways to encourage them to engage in community activities. TVET is one of such education processes which has focused on work-based learning in the community. The workplace learning of TVET is informal type apprenticeship which has no formal curriculum, neither has it formal structure of learning process. Instead it has taken the basic norms of transformational learning through which social transformation is possible. Some educational institutions have arranged informal type of educational programs like internships, practical work, project work, field visit and so on which are insufficient to make people independent in learning. They have followed a type of alternate mode of education which is quite insufficient to make students self-reliant.

So there is a huge gap between the product of TVET and general education to kick start for entrepreneurship. Different studies prove that average income, skill increment, work efficiency, apprenticeship, and entrepreneurship skill are much higher with vocational learners. Moreover, they need the support of transformational skills from 
formal education equally. In this way, the combination of formal, non-formal and informal apprenticeships along with formal education are much better from productive and development perspectives (Sharma, 2012). The upcoming topic is going to establish the relation between diversified education and transformation.

\section{Importance of Diversified Education for Social Change}

Unitary education system can't produce dynamic manpower that is decked with soft and hard skills. We need 'diversified schools' and educational systems which can mingle the ideas of hard and soft skills together to produce good, efficient, and effective manpower. We need multi-purpose manpower that can combine both sorts of qualities of academic and vocational education together. Since we have developed inclusive educational system, we can have the flavor of both general and vocational education which can transform students from existing rule of teaching to the practical-based learning methods. Such manpower can develop valuable insights within vocational areas that can also progress for further higher education like in the developed economies (Adhikari, 2013).

The general content with vocational training can be a panacea to solve the existing unemployment problem of the developing countries. If we apply such approach in education, we can shift from supply driven approach of TVET to the demand-driven approach which will be milestone for economic and social development. We need connection between school and workplace to make our education system productive, effective, and efficient. So this is the time to step ahead for the solution. We need to apply "strong school-industry cooperation internships, industry-based training for faculty members, education for mid-career industry employees, joint college/industry research programmes" to make our manpower more effective and efficient (Maclean \& Pavlova, 2013, p. 67). Such type of cooperation and coordination need broad thinking and working style to ensure opportunities for the graduates. It indicates more inclusive plans and policies along with committed leaders and educationists. Hence we can apply diversified model of education system under TVET rather than under unitary model which is existing these days.

The combination of vocational and general education can address the need of the labour market and entry into higher education. Such model can be regarded as transformative model in these days as it has ensured dual opportunities to the stakeholders. In real sense it doesn't let learner unemployed as one has got them together. Such transferable skills will make people perfect in diverse fields to get job or to pursue higher education. Hence there is intrinsic relation between TVET and general education as they are the siblings of a family. Unless there is no transformation in individual through education and work, no transformation in family is expected possible. We can feel the same relation among educational fields to be combined to get better output. The learner can choose either pathway of higher education or job in such dual education system. The provision of such permeability can encourage the learner to take vocational education as secure and prestigious stream of education. Hence the negativity of TVET can be corrected (Renold \& Caves, 2017).

The existing education system has a logic that knowledge gained in school or colleges can be practiced in field after completion of one to the other. Unlike that the work-based education has different provision because it has addressed the personal needs of the learner and the place. Thus vocational education is different from formal education as it has focused on field-based inclusive education. Unless we can't educate individual in a such way, it's impossible to get even basic motto of education. The oppositional logic of formal, informal and non-formal education can be solved only with the combination and transformation of individual characters with inclusive education. Every individual needs 'intra-psychological change' to understand the real nature of TVET and general education so the problem can be solved (Billet, 2013). Unless individuals can't learn about their capacities, we can't instruct them in the field of TVET.

It is necessary to correct social and cultural environments and activities of the society through educational transformation. After all work experience is a sustainable motto of education other than the motto of general education. An individual can learn through daily activities, interactions, engagement, and experience when they work to produce goods and services. Hence there is the need of diversified education to address such issues in individual basis. The next topic is going to elucidate the value of TVET for legitimizing social practices.

\section{Legitimizing Social Practices through TVET}

The knowledge of apprenticeship owned by the artisans/ mentors is much a social identity rather than the personal property in a broad sense. Vocational education has the responsibility to advert such knowledge to new generation and to carry out the responsibility of the society. In this way, social transformation is only possible through educational transformation. Thinking broadly, we need to connect the traditional apprenticeship with modern scientific knowledge to make it popular and more productive. So it's necessary to provide knowledge of mathematics and science along with apprenticeship to make it more reliable for the incumbents (Gamble, 2013).

Social transformation through educational transformation is possible only when education is effective. TVET education can bridge between the world of work and education. We could go to the society with possible knowledge that helps in new knowledge formation. Accordingly it has been known as transformation. The learner 
is an 'active agent' in strengthening this relationship (Watts, 2013). The demand of these days is that a person can become the agent of change in the society. Truly speaking, the motto of transformative education lies in an individual with broad mindset. Such people would learn from their experience, think critically and act autonomously to be an independent and innovative citizen of the country. Education that only generates hard skills is not useful in this context. We need transformative education which can foster generic or transferable skills that can be the agent of change. It has developed the characteristics such as "innovation, creativity, energy and singlemindedness" that are the need for present generation (Badawi, 2013, p. 279).

TVET education has strong capability to produce hard skilled manpower, especially in developing countries, which is in antagonism with general education at present. However, some of the countries like Germany and South Korea have been able to manage balance between these contrasting educational approaches. There is the need of TVET program to enhance "learning, workplace partnerships, high skills training, broader specializations, a greater role for information and communications technology" to get maximum output in the society (p 293). The institutions which can produce transferable manpower come into existence in the future which is possible only with the mixture of general and vocational education. Tikly (2013) regarded such education as the 'glue' that can keep all the programs together. Human capital theory also seems to be harsh, in this sense, because it has promoted the capitalist philosophy only rather than socialist ideals. Our main motto of social change is through the transformation of education that can contribute for national development. We have thought to change those individuals who "can act to bring about changes they value" (p. 19). Hence the change in personality is the change in society which is possible only with educational ointment.

\section{Conclusion}

TVET is a new and mysterious educational approach of the era in creation of employment and solution of unemployment problems in developing countries. It's a paradox whether to develop as educational paradigm or to take it as side factor of formal education only. The problem arises with the misunderstanding of TVET education as second-chance education. As a corollary, the developing countries lag behind in employment creation. Different social problems which are existing in local areas are distinct in comparison to global issues. It happens due to the illiterate, ignorant, and indifferent locals who need to see light in darkness. They have been pursuing industries as nightmare of employment ignoring the fact that the pivotal matter lies at the local level. They can improve it with their active involvement in development activities with the transformed education like TVET. Hence it is the need of individual and community as it has created great opportunities of skill development for self-sufficiency. It promotes work-based learning culture in collaboration with local team members according to their need. It also promotes collaboration among community people uplifting the status of disadvantages, marginalized, excluded, disabled etc. with the help of artisans/mentors. TVET has direct contribution to the employment than general education as the purpose of education is to increase employability.

The underlying fact is that TVET can transform job holder to entrepreneur if it has been mingled with formal education. If we can mix the qualities of general education like communication skills, problem-solving skills, leadership skills, critical thinking skills and teamwork skills along with TVET education, we can produce efficient and effective manpower for the development of the nation. The development imperatives like skills, employment and economic growth can be achieved with the improvement of TVET education with formal mixture only. The schooling discourse, learning in school not outside, can be transformed along with the development of transformational education. The motto of vocational education has connection with lifelong learning that is the root of diversified education. Personal needs, interests, attitudes, characters, relations and so on can be addressed in diversified education.

\section{References}

Adhikari, P. K. (2013). Vocational skill development and policy learning. (R. Karki, Ed.) Technical and Vocational Education and Training Development Journal, 1 (13), 9-13.

Apelgren, B.-M., Burnard, P., \& Cabaroglu, N. (2015). Theory use in teacher research. (p. B. al., Ed.) Transformative teacher research, 3-12.

Badawi, A. A. (2013). TVET and entrepreneurship skills. Revisiting global trends in TVET: Reflections on theory and practice, $275-308$.

Bhandari, U. (2013). Technical vocational education and training (TVET) development and social inclusion in Nepal. (R. Karki, Ed.) Technical and vocational education and training development journal, 1 (13), 29-36.

Billet, S. (2013). Learning through practice: beyond informal and towards a framework for learning through practice. Revisiting global trends in TVET: Reflections on theory and practice, 123-163.

Cavanagh, D., Shaw, G., \& Wang, L. (2013). Technical and vocational education and training, and skills development for rural transformation. Revisiting global trends in TVET: Reflections on theory and practice, 309-340.

Gamble, J. (2013). Why improved formal teaching and learning are important in technical and vocational education 
and training (TVET). Revisiting global trends in TVET: Reflections on theory and practice, 204-238.

Kafle, A. (2014). Individualized learning. (R. Karki, Ed.) Technical and Vocational Education and Training Development Journal, 1 (14), 41-47.

Kemmis, S., \& McTaggart, R. (2007). Participatory action research: Communicative action and the public sphere. In D. \&. Lincoln.

Maclean, R., \& Pavlova, M. (2013). Vocationalization of secondary and higher education: pathways to the world of work. Revisiting global trends in TVET: Reflections on theory and practice, 40-85.

McTaggart, R. (1994). Participatory action research: Issues in theory and practice. Educational action research, 2 (3).

Renold, U., \& Caves, K. (2017). Constitutional reform and its impact on TVET governance in Nepal. Geneva: KOF studies.

Romero, A., Cammoarota, J., Dominguez, K., Valdez, L., Ramirez, G., \& Hernandez, L. (2008). "The opportunity if not the right to see" the social justice education project. In J. Cammarota, \& M. Fine (Eds.), Revolutionizing Education:Youth Participatory Action Research in Motion. New York: Routledge.

Rood, R. V. (2014). Identification for EU support to TVET sector. Hempstead: HTSPE Limited.

Sharma, T. N. (2012). Poverty Reduction Initiatives in Nepal with Special Reference to Technical Education and Vocational Training. (R. Karki, Ed.) Technical and vocational education and training development journal, 1 (12), 1-12.

Slavish, G. M., \& Zimbardo, P. G. (2012). Transformational teaching: Theoretical underpinnings, basic principles and core methods. Educational Psychological Review.

Stone, J., \& Davidson, N. (2015). Future qualities: Transformational, the context for next generation. (N. Davidson, \& M. Herring, Eds.) Emerging qualities of effective teaching: Traditional, responsive, and transformative.

Sweet, R. (2013). Work-based learning: Why? How? Revisiting global trends in TVET: Reflections on theory and practice, $164-203$

Tikly, L. (2013). Reconceptualizing TVET and development: A human capability and social justice approach. Revisiting global trends in TVET: Reflections on theory and practice, 1-39.

Watts, A. G. (2013). Career guidance and orientation. Revisiting global trends in TVET: Reflections on theory and practice, $239-274$

Winch, C. (2013). The attractiveness of TVET. Revisiting global trends in TVET: Reflections on theory and practice, $86-122$.

Zuljan, M. V., \& Vogrinc, J. (2010). The factors of encouraging teacher innovation from the perspective of teachers and headteachers. In M. V. Zuljan, \& J. Vogrinc (Eds.), Facilitating effective student learning through teacher research. Slovenia: Ljubljana: Faculty of Education. 